Bangham et al.4, it is believed that the physical picture presented can be used for interpreting the rheological properties and especially the caking phenomena. The state of ash in caking coal as an active 'filler' is not specified; but it is inferred that the active filler in general has strong affinity for the matrix molecules and is finely dispersed, so that the 'active' ash is likely to correspond to the inherent ash of coal.

Recently, we recognized interesting anomalies in these values for a Japanese bituminous caking coal, Takashima, with an average volatile matter of 38 per cent (dry ash-free), as illustrated in the graph ; minima were shown in the range of 2 per cent of ash-volume concentration, and maxima in the 8-10 per cent range. These results seem to support the theory that the inorganic matter plays a significant part in the structure of coal and its properties. The linear relationship between the values and ash content is considered to be in the range of 2-10 per cent of ash for this sample.

It is well known in rubber science that elastic constant, viscosity coefficient and tensile strength at first decrease with loading with carbon black (up to 10 per cent by volum $\Theta^{5}$ ), followed by an increase of these properties for greater loadings up to a point ( 30 per cent by volume ${ }^{5}$ ) where the stiffening ends by overloading. The similarity in variations of rheological properties between the two systems, with 'filler' and matrix, is interesting, despite the numerical differences in ranges of filler content. It may be suggested that the first minima at 2 per cent of ash content correspond to the state where the micellar spheres, in which the coal molecules are solvated by ash particles as nuclei, first touch each other, forming a sort of scaffolding, and the second maxima at approximately 10 per cent of ash content represent the point where the micellar spheres form a closepacked state.

Taking a sample with $10 \cdot 13$ per cent ash by volume of Takashima coal, the specific surface area was

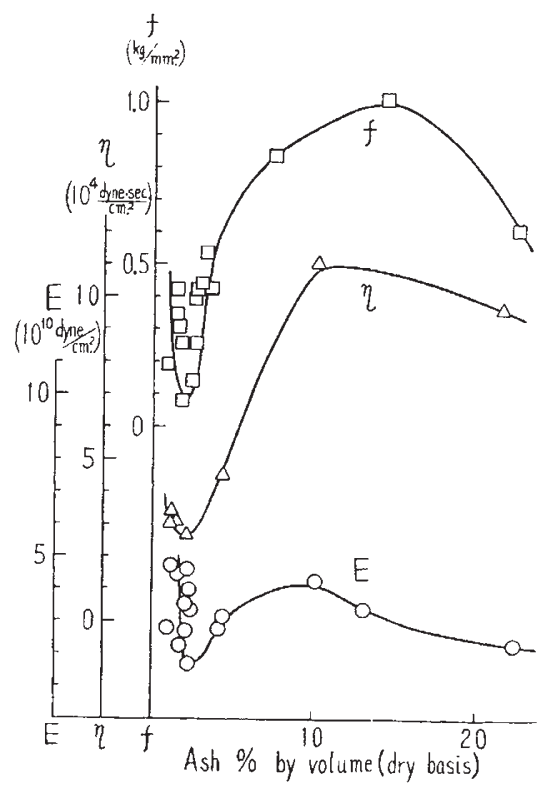
Experimental results on the variations of rheological properties
of Takashima bituminous coal : $E$, Young's modulus; $\eta$, internal viscosity coefficient ; $f$, breaking strength found by the iodine adsorption method ${ }^{6}$ at $25 \cdot 0^{\circ} \mathrm{C}$. to be $9.51 \times 10^{4} \mathrm{~cm} .^{2} / \mathrm{gm}$. (dry bosis) and the density in methanol was $1 \cdot 24\left(25 \cdot 0^{\circ} \mathrm{C}\right.$.). Assuming the closepacked state of micellar spheres for the range of 10 per cent ash and that each micelle has an untruncated surface, the radius of the sphere was calculated as $2540 \mathrm{~A}$., and the radius of the ash particles serving as nuclei was estimated as $1160 \mathrm{~A}$. ; these dimensions of ash are nearly the same as those of some kinds of carbon blacks. The micellar dimensions are expected to be largest for caking coals, because the solvation factors of molecules around ash are highest ${ }^{1,2}$ and, as is widely recognized, the variation of the specific surface area with the rank of coals shows a minimum for the bituminous coal group.

The detailed results of this investigation will be published in Bull. Chem. Soc. Japan, as part of an investigation of the rheology of coal. I am indebted to Mr. H. Tani for help in the experiments.

Resources Research Institute, Katsuya InOUYe

Saitama-Kawaguchi, Japan.

Aug. 20.

${ }^{1}$ Inouye, K., J. Colloid Sci., 6, 190 (1951)

${ }^{2}$ Inouye, K., Bull. Chem. Soc. Japan (in the press).

${ }^{3}$ Inouye, K., and Tani, H., Bull. Chem. Soc. Japan (in the press).

" Bangham, D. H., Franklin, R. E., Hirst, W., and Maggs, F. A. P., Coal Research, 153 (1948).

${ }^{5}$ Guth, E., J. App. Phys., 16, 20 (1945).

- Inouye, K., J. Fuel Soc. Japan, 29, 112 (1950).

\section{Diffusion of Silicon in Ferrite}

WE have recently carried out some measurements on the diffusion of silicon at low concentrations in ferrite at one temperature near to the melting point. Specimens (cylinders of $\frac{1}{2}$ in. diameter) were made of pure iron butt-welded to a 3-4 per cent silicon iron alloy. These were heated for differing times at the temperature $1,435 \pm 5^{\circ} \mathrm{C}$., cooled and sectioned along a plane perpendicular to the weld interface. The diffusion of silicon into the iron across the interface was measured by traversing the section with a spectrograph spark. By correcting for the finite size of the sparked zone and standardizing the spectrograph with samples of known silicon content, curves of silicon concentration versus distance were plotted. The diffusion coefficient of silicon was obtained by applying Fick's law and the result (mean of five determinations) was $D_{\gamma}=1.1 \times 10^{-7} \mathrm{~cm} .{ }^{2} / \mathrm{sec}$. The grain-sizes of the specimens were large enough to assume that at the temperature used the contribution of grain-boundary diffusion was small, and it is thought that overall error in $D$ should not be greater than \pm 20 per cent.

The variation of $D$ with temperature may be calculated if Zener's theory ${ }^{1}$ is assumed. Depending on whether vacancy or ring diffusion occurs, respectively, $D_{\gamma}=16 \exp (-64,000 / R T)$, or $310 \exp (-74,000 / R T)$ cm. ${ }^{2} / \mathrm{sec}$.

\section{F. J. Bradshaw \\ G. HOYLE \\ K. SPEIGHT}

Metallurgy (General) Divisional Laboratory,

British Iron and Steel Research Association, Royal School of Mines, London, S.W.1. Oct. 1.

'Zener, C., J. App. Phys., 22, 372 (1951). 